DOI: $10.1113 /$ EP088887

\title{
Time-course of neuromuscular responses to acute hypoxia during voluntary contractions
}

\author{
Daniel J. McKeown ${ }^{1}$, Chris J. McNeil ${ }^{2}$, Michael J. Simmonds ${ }^{3}$, and Justin J. Kavanagh ${ }^{1}$ \\ ${ }^{1}$ Neural Control of Movement Laboratory, Menzies Health Institute Queensland, Griffith \\ University, Gold Coast, Queensland, Australia \\ 2 Integrated Neuromuscular Physiology Laboratory, Centre for Heart, Lung, and Vascular \\ Health, School of Health and Exercise Sciences, University of British Columbia, Kelowna, \\ British Columbia, Canada \\ ${ }^{3}$ Biorheology Research Laboratory, Menzies Health Institute Queensland, Griffith \\ University, Gold Coast, Queensland, Australia
}

Key words: Voluntary activation; Corticospinal excitability, Hypoxemia, Fatigue

Word count: 6572

References: 49

Subject Area: Environmental and exercise physiology and/or Muscle physiology

\section{Corresponding author}

Daniel J. McKeown

This is an Accepted Article that has been peer-reviewed and approved for publication in Experimental Physiology, but has yet to undergo copy-editing and proof correction. Please cite this article as an Accepted Article; doi: 10.1113/EP088887.

This article is protected by copyright. All rights reserved. 
School of Allied Health Sciences

Griffith University, Gold Coast

Queensland 4222, Australia

Email: daniel.mckeown@griffith.edu.au

Tel: +61 (7) 55528057

Fax: +61 (7) 55528674

\title{
NEW FINDINGS
}

- What is the central question of this study?

How does acute hypoxia alter central and peripheral fatigue during brief and sustained maximal voluntary muscle contractions?

- What is the main finding and its importance?

Perception of fatigue during muscle contractions was progressively increased for $2 \mathrm{hr}$ after hypoxic exposure. However, an increase in motor cortex excitability and decrease voluntary activation of skeletal muscle was observed across the entire protocol when performing brief $(3 \mathrm{~s})$ maximal contractions. These adaptations are abolished if the brief contraction is held for a $20 \mathrm{~s}$ duration, which is presumably due to a successful redistribution of blood to overcome the reduced oxygen content.

\begin{abstract}
Few studies have examined the time course of changes in the motor system following acute exposure to hypoxia. Thus, the purpose of this study was to examine how acute hypoxia affects corticospinal excitability, voluntary activation (VA), and perception of fatigue during brief ( $3 \mathrm{~s})$ and sustained (20 s) maximal voluntary contractions (MVCs). Fourteen healthy individuals $(23 \pm 2.2 \mathrm{yr} ; 4$ female $)$ were exposed to a hypoxia and a sham condition. During hypoxia, peripheral blood oxygen saturation $\left(\mathrm{SpO}_{2}\right)$ was titrated over a $15 \min$ period and remained at $80 \%$ during testing. Corticospinal excitability and VA were assessed before
\end{abstract}

This article is protected by copyright. All rights reserved. 
titration (Pre), $0 \mathrm{hr}, 1 \mathrm{hr}$, and $2 \mathrm{hr}$ after. At each time point, the brief and sustained elbow flexion MVCs were performed. Motor evoked potentials (MEP) were obtained using transcranial magnetic stimulation (TMS), superimposed and resting twitches were obtained from motor point stimulation of biceps brachii to calculate level of VA, and ratings of perceived fatigue were obtained with a modified CR-10 Borg scale. A condition by time interaction was detected for the CR-10 Borg scale, where perception of fatigue progressively increased throughout the hypoxia protocol. However, main effects of MEP area and VA indicated that corticospinal excitability increased, and VA of the biceps brachii decreased, across the hypoxia protocol. Given that these changes in MEP area and VA were only seen when performing the brief MVCs (and not during the sustained MVCs), performing longer contractions may overcome reduced oxygen content by redirecting blood flow to active areas of the motor system.

\section{INTRODUCTION}

A reduction in blood oxygenation can significantly impair the neural activation of muscles across a range of contraction tasks (Billaut et al., 2013; Goodall, Gonzalez-Alonso, Ali, Ross, \& Romer, 2012; McKeown, Simmonds, \& Kavanagh, 2019; Ruggiero, Yacyshyn, Nettleton, \& McNeil, 2018). Given that descending drive to muscles is modulated by supraspinal and spinal circuits, several studies have profiled these areas of the nervous system in response to acute exposure to hypoxia. A variety of findings have been reported, with corticospinal excitability documented to increase (Goodall, Twomey, \& Amann, 2014; Ruggiero \& McNeil, 2019), decrease (Goodall, Ross, \& Romer, 2010), or show no change (Rupp, Racinais, Bringard, Lapole, \& Perrey, 2015; Szubski, Burtscher, \& Loscher, 2006, 2007) in response to hypoxic exposure. These equivocal findings may reflect methodological 
variations, where the duration of hypoxic exposure, and the type of muscle activity that is examined, can substantially differ between studies.

Motor unit discharge rate during isometric elbow flexion, for example, is unaffected during the first hour of acute hypoxia (peripheral blood oxygen saturation, $\mathrm{SpO}_{2} 80 \%$ ). However, after experiencing $2 \mathrm{hr}$ of $80 \% \mathrm{SpO}_{2}$ a subject-specific response in low-threshold motor unit activity emerges in healthy individuals. Specifically, participants who desaturate to $80 \%$ $\mathrm{SpO}_{2}$ in a relatively short period (20 min) exhibit decreased motor unit discharge rates compared to those who desaturate more slowly (McKeown et al., 2019). Corticospinal excitability of the quadriceps is also unaffected after $1 \mathrm{hr}$ of hypoxic exposure $\left(\mathrm{SpO}_{2}: 86 \%\right)$ but increased after $3 \mathrm{hr}$ (Rupp et al. 2012). Of note, voluntary activation (VA) remains unchanged at $3 \mathrm{hr}$, which highlights that hypoxia-related changes identified from cortical stimulation may not necessarily reflect the output of the motor system during active muscle contractions (Rupp et al., 2012). Other investigations have reported a fatigue-related reduction in VA is greater when the availability of oxygenated blood is reduced (Amann, Blain, et al., 2011; Sidhu et al., 2014). However, the exercise is typically prolonged, or performed to exhaustion, so there is substantial opportunity for greater metabolite accumulation (accompanied by enhanced group III/IV afferent feedback) owing to reduced availability of oxygenated blood (Goodall et al., 2010; Ruggiero et al., 2018; Rupp et al., 2012; Rupp et al., 2015; Szubski et al., 2007). As the effect of hypoxia on the motor system appears to be heavily dependent on the duration of muscle activation and contraction task being performed, it is uncertain how VA of the elbow flexors is affected by brief and sustained isometric contractions in the presence of a constant exposure to hypoxia.

The purpose of this study was to examine how acute hypoxia alters central and peripheral mechanisms underlying maximal voluntary contractions (MVC). $\mathrm{SpO}_{2}$ was titrated to $80 \%$ 
within $15 \mathrm{~min}$, and the activation characteristics of the elbow flexors were assessed following a brief (3 s) MVC protocol, and following a sustained (20 s) MVC protocol. A time-course of neuromuscular responses was obtained by performing motor cortical, brachial plexus, and motor point stimulation before titration to $80 \% \mathrm{SpO}_{2}$, and then immediately after, $1 \mathrm{hr}$ after, and $2 \mathrm{hr}$ after titration. It was hypothesised that exposure duration to $80 \% \mathrm{SpO}_{2}$ would be a (negative) determinant of neural mechanisms of muscle activation. We also anticipated that the disparity between hypoxia-related responses and responses during a sham condition would be most apparent following the sustained MVC when there is a greater metabolic demand, compared to the brief MVC.

\section{MATERIALS AND METHOD}

\section{Ethical approval}

Each participant provided written and witnessed informed consent prior to undertaking testing. All experimental procedures were approved by the Griffith University Human Research Ethics Committee (reference number: 2018/838). The study conformed to the standards set by the Declaration of Helsinki, except for registration in a database.

\section{Participants}

Fourteen healthy individuals $(23 \pm 2.2 \mathrm{yr} ; 4$ female $)$ volunteered to participate in the experiment. All participants completed a medical history questionnaire prior to testing, which contained exclusion criteria specific to reduced blood oxygenation, magnetic stimulation, and electrical stimulation. Participants were not permitted to be taking any form of CNS-active medications and were instructed to refrain from any form of stimulant or depressant, such as

This article is protected by copyright. All rights reserved. 
caffeine or alcohol, and also moderate-to-high intensity exercise for at least $12 \mathrm{hr}$ before testing.

\section{Experiment design}

The current study was a two-way, sham-controlled, cross-over design where participants attended two testing sessions that were separated by $1 \mathrm{wk}$. For safety reasons this was a single-blind study, as an investigator in the room needed knowledge of the hypoxia condition and monitored $\mathrm{SpO}_{2}$ throughout the testing sessions. In one session a hypoxia condition was employed and in the other session a sham condition was employed. The sham condition reflected all hypoxia testing procedures except for reduction of $\mathrm{SpO}_{2}$. The administration of the conditions was counterbalanced to avoid order effects, where half of the participants underwent the hypoxia condition in their first session, and the other half of participants underwent the sham condition in their first session.

\section{FIGURE 1 HERE}

\section{Instrumentation}

Hypoxia intervention. An altitude simulator (Altitude Training Systems, ATS200HP, Australia) and a sealed facemask was used to reduce $\mathrm{SpO}_{2}$ to $80 \%$ via regulation of the fraction of inspired oxygen $\left(\mathrm{F}_{\mathrm{I}} \mathrm{O}_{2}\right)$. Since sensitivity to altered oxygen availability is quite variable between individuals (Rojas-Camayo et al., 2018), $\mathrm{F}_{\mathrm{I}} \mathrm{O}_{2}$ was titrated over a $15 \mathrm{~min}$ period for each individual and remained at the desired $\mathrm{F}_{\mathrm{I}} \mathrm{O}_{2}$ that consequently resulted in $80 \%$ $\mathrm{SpO}_{2}$ for the $2 \mathrm{hr}$ experimental protocol. $\mathrm{SpO}_{2}$ and heart rate was monitored at all times using a pulse oximeter (Model 7500, Nonin Medical Inc, Minnesota, USA) attached to the middle 
finger of the non-active hand. Although other physiological characteristics such as ventilation, heart rate variability, and cardiac output, are known to be affected with changes in oxygenation, these measures were not a focus of the current study and were not collected during testing. Participants were carefully monitored for symptoms of acute mountain sickness (AMS), including dizziness, headaches, sleepiness, and nausea throughout the experimental protocol. Participants scored their experience of each individual symptom as either 0 (absent), 1 (mild), 2 (moderate), or 3 (severe). Symptoms were then calculated as an accumulative score to represent the severity of AMS symptoms experienced by a participant at a time point. The Lake Louise acute mountain sickness (AMS) survey was employed before titration (Pre), and immediately after $(0 \mathrm{hr}), 1 \mathrm{hr}$ after, and $2 \mathrm{hr}$ after titration.

Electromyography and force. Participants sat in a chair with their right arm fixed in a custombuilt force transducer to measure isometric elbow flexion torque. The shoulder and elbow were placed in 90 degrees of flexion and the participant's arm was fixed to the device at the wrist (Kavanagh, McFarland, \& Taylor, 2019; McNeil, Giesebrecht, Khan, Gandevia, \& Taylor, 2011). A precision S-beam load cell (PT4000, PT Ltd, New Zealand) with a $1.1 \mathrm{kN}$ range and full-scale output of $3 \mathrm{mV} / \mathrm{V}$ was used to measure elbow flexion force which was later converted to elbow flexion torque. Surface electromyography (EMG) was recorded from the biceps brachii and triceps brachii by attaching circular $24 \mathrm{~mm} \mathrm{Ag} / \mathrm{AgCl}$ electrodes (Kendall Arbo) on each muscle in a bipolar arrangement (24 mm inter-electrode distance). A ground electrode was placed on the acromion of the test limb. Force and EMG signals were sampled at $2000 \mathrm{~Hz}$ using a 16-bit analog-to-digital converter (CED 1401; Cambridge Electronic Design, Cambridge, UK) and Spike2 software (version 7.02; Cambridge Electronic Design). EMG signals were amplified $(\times 300)$ and bandpass filtered $(10-1000 \mathrm{~Hz})$ using a CED 1902 amplifier (Cambridge Electronic Design) whereas force signals remained unfiltered.

This article is protected by copyright. All rights reserved. 
Motor point stimulation. Intramuscular nerve fibres of the elbow flexors were stimulated with single supramaximal pulses of $100 \mu$ s duration via a constant current peripheral nerve stimulator (DS7AH, Digitimer Ltd., UK). A surface anode was positioned over the distal biceps brachii tendon and a surface cathode was positioned over the muscle belly of the biceps brachii. Optimal positioning of the surface cathode was determined by using a motor point stimulating pen, and was based on the highest elicited elbow flexor twitch force. Maximal resting twitch was determined by progressively increasing the stimulus intensity until there was no longer increases in the elicited elbow flexor twitch force. The stimulus intensity was then set at $20 \%$ above the maximal resting twitch for stimulations performed during the sham protocol $(248 \mathrm{~mA} \pm 97 \mathrm{~mA}, 144 \mathrm{~mA}-384 \mathrm{~mA})$ and hypoxia protocol (265 $\mathrm{mA} \pm 86 \mathrm{~mA}, 132 \mathrm{~mA}-384 \mathrm{~mA})$. There was no significant difference in stimulus intensity between the sham and hypoxia protocols $(P=0.07)$.

Brachial plexus stimulation. A second constant current peripheral nerve stimulator (DS7AH, Digitimer, Ltd., UK) was used to deliver single electrical pulses of $100 \mu$ s duration to the brachial plexus (Erb's point) to determine the maximum compound action potential (Mmax) of the biceps and triceps brachii. A surface anode was positioned over the ipsilateral acromion and a surface cathode was positioned over the supraclavicular fossa. Positioning of the cathode was once again determined by using a motor point stimulating pen. Optimal stimulus intensity was determined by progressively increasing the stimulus intensity until the Mmax of both the biceps and triceps brachii was reached. The stimulus intensity was then set at 30\% above that used to obtain Mmax during the sham protocol $(191 \mathrm{~mA} \pm 61 \mathrm{~mA}, 97 \mathrm{~mA}$ - $325 \mathrm{~mA})$ and hypoxia protocol $(190 \mathrm{~mA} \pm 67 \mathrm{~mA}, 130 \mathrm{~mA}-325 \mathrm{~mA})$. There were no significant differences in stimulus intensity between the sham and hypoxia protocols $(P=$ $0.41)$.

This article is protected by copyright. All rights reserved. 
Motor cortical stimulation. A Magstim $200^{2}$ TMS unit (Magstim Co., UK) was used to evoke MEPs in the test limb. A circular coil (90 mm Remote Coil, Magstim Co., UK) was positioned over the vertex to elicit MEPs in the biceps and triceps brachii muscles. The coil was oriented to preferentially activate the left motor cortex projecting to the participant's right arm. The stimulator output (65-85\% maximum stimulator output) was set at an intensity that generated a large MEP in the biceps brachii ( $>60 \%$ of Mmax during 50\% MVC). Once established, the stimulator output remained constant throughout testing.

Rating of perceived fatigue. Psychophysical measures of fatigue were obtained using a CR-10 Borg scale (Borg, 1982) which was administered following each contraction during the hypoxia and sham protocols. The CR-10 Borg scale is regularly used during experiments involving exercise, it is easy for the participant to interpret and respond to, allowing scores to be collected rapidly at specific time points. Participants were informed that the CR-10 Borg scale was a measure of their subjective experience of muscle fatigue (i.e. how fatigued their biceps brachii muscle felt), regardless of objective measures of fatigue (i.e. their performance during the contraction tasks). Before each testing session, participants were provided a printout of the CR-10 Borg scale where they were asked the question 'how fatigued does your biceps brachii muscle feel?'. Participants were instructed that the lowest value on the scale represented 'no fatigue at all where you feel that you are able to fully contract your muscle', and the highest value on the scale represented 'maximal fatigue where you feel that you are unable to contract your muscle'.

\section{Experimental Procedures}

Participants visited the laboratory on two occasions, where they were exposed to a sham or hypoxia condition that titrated $\mathrm{SpO}_{2}$ to $80 \%$ within 15 min. Blocks of measurements were performed before titration (Pre), and immediately after ( $0 \mathrm{hr}), 1 \mathrm{hr}$ after, and $2 \mathrm{hr}$ after

This article is protected by copyright. All rights reserved. 
titration. Each block of measurements took $\sim 20$ min to complete and participants were given $\sim 40$ min of rest before the next block of measurements (Figure 1A). For both the brief and sustained MVC protocol, participants were provided with visual feedback of instantaneous force output via a computer monitor that was placed in front of them. For maximal contractions, participants were encouraged to pull on the force transducer maximally for the duration of the contraction. A target trajectory was then calculated and provided on the computer monitor $(75 \%, 50 \%$, and then $25 \%$ MVC). Participants were required to match their force output with the target trajectory to the best of their ability.

Brief MVC protocol. At the commencement of the experimental protocol, participants were instructed to perform a $3 \mathrm{~s}$ brief MVC, and motor point stimulation was delivered to the biceps brachii at maximal force output and $2 \mathrm{~s}$ later to the resting potentiated muscle (Figure 1B). After a 1 min rest period participants performed a graded contraction, commencing at MVC which then decreased to $75 \%, 50 \%$, and then $25 \%$ of MVC. Each contraction intensity was held for $4 \mathrm{~s}$ where TMS was delivered to the motor cortex, followed by electrical stimulation to the brachial plexus $2 \mathrm{~s}$ later. That is, TMS and brachial plexus stimulation were both applied at each contraction level. Participants were then given 2 min rest to mitigate the effects of fatigue before performing the next set of contractions. After completing three sets of the brief MVC protocol, participants were given 3 min of rest before performing the following protocol.

Sustained MVC protocol. This protocol consisted of performing a $20 \mathrm{~s}$ maximal elbow flexion which was then decreased in $25 \%$ increments $(75 \%, 50 \%$, and $25 \%$ of MVC; Figure 1C). Participants were required to hold each contraction intensity for $4 \mathrm{~s}$ where TMS was delivered followed by brachial plexus stimulation $2 \mathrm{~s}$ later. That is, TMS and brachial plexus stimulation were both applied at each contraction level. Participants were then instructed to 
perform a brief MVC immediately after the fatiguing protocol where motor point stimulation was delivered to the biceps brachii at maximal force output and $2 \mathrm{~s}$ later in the resting potentiated muscle. Similar to the brief MVC protocol outlined above, the absence of rest phases throughout this protocol prevented any recovery from occurring between contraction intensities. This was particularly important for retaining characteristics of central fatigue that may have emerged during the sustained MVC. However, once participants had finished the contraction protocol, they were then given 2 min rest before performing the next set. A total of three sustained MVC sets were performed during each block of measurements during the hypoxia and sham conditions.

\section{Data analysis}

All force and EMG data were analysed offline using Spike2 (version 7.02, Cambridge Electronic Design). Following data collection, force data were converted to torque. Maximal voluntary torque and the root mean square amplitude of biceps $\mathrm{EMG}\left(\mathrm{EMG}_{\mathrm{RMS}}\right)$ were calculated from MVCs during the brief and sustained tasks using a $50 \mathrm{~ms}$ window preceding the motor point stimulation artefact. Amplitudes of motor point superimposed and resting twitches were calculated from increases in torque output following electrical stimulation. VA was calculated as $[1-($ superimposed twitch torque/resting twitch torque $)] \times 100 \%$, where the superimposed and resting twitch were associated with the same contraction. MEP area was measured from each TMS stimulation and then normalised to the area of the Mmax collected during the same contraction to account for activity-dependent changes in muscle fibre action potentials. Activation values, maximal voluntary torque, $\mathrm{EMG}_{\mathrm{RMS}}$, MEP area, Mmax area, and rating of perceived fatigue scores were averaged across the 3 repeated contractions at each time point. Scores from the Lake Louise AMS survey were reported as an accumulative 
score of symptoms. Change scores were calculated for MVC torque, $\mathrm{EMG}_{\mathrm{RMS}}, \mathrm{MEP}$ area, AMS survey scores, and perception of fatigue where measurements obtained at the $0 \mathrm{hr}, 1 \mathrm{hr}$, and $2 \mathrm{hr}$ time points were subtracted from 'Pre' measurements.

\section{Statistical analysis}

Normality of data was assessed using Shapiro-Wilk tests, which indicated all data were normally distributed. Greenhouse-Geisser corrections were applied when assumptions of sphericity were violated. Differences between Pre measurements in the sham and hypoxia conditions were assessed using paired-sample t-testing. The accumulated Lake Louise AMS survey scores and rating of perceived fatigue were assessed independently at each time point using Wilcoxon matched-pairs signed rank tests. Maximal voluntary torque, $\mathrm{EMG}_{\mathrm{RMS}}$, $\mathrm{MEP}$ area normalised to Mmax area, superimposed twitch, resting twitch, and level of VA were analysed independently for the brief MVC task and the sustained MVC task. For each of these variables, a mixed-effect model with factors of condition (sham, hypoxia) and time point (Pre, $0 \mathrm{hr}, 1 \mathrm{hr}, 2 \mathrm{hr}$ ) was used. In the event of a significant main or interaction effect, post hoc analysis was performed with Dunnett's multiple comparisons tests to identify how the condition influenced the dependent variables at each time point. All statistical procedures were performed using IBM SPSS Statistics (version 26) with alpha levels set at $<0.05$. Data in tables and figures are presented as means \pm standard deviations, unless stated otherwise.

This article is protected by copyright. All rights reserved. 


\section{RESULTS}

\section{Self-reported symptoms of hypoxia}

All subjects were able to complete the experimental protocol during both the sham and hypoxic conditions. Very mild symptoms of AMS were experienced by participants during the hypoxia exposure. A total of 82 individual scores $(\operatorname{sham}=15$, hypoxia $=67)$ were reported for the 14 subjects across both conditions of the experimental protocol (Table 1). There was a statistically significant median difference in AMS score at the $1 \mathrm{hr}$ and $2 \mathrm{hr}$ time points $(P \leq 0.04)$, where participants experienced greater AMS symptoms during hypoxia compared to sham (Figure 2).

\section{TABLE 1 AND FIGURE 2 HERE}

\section{MVC torque and $E M G_{R M S}$}

No differences in Pre measurements were seen for MVC torque and $\mathrm{EMG}_{\mathrm{RMS}}$ during the brief $(P \geq 0.54)$ or sustained $(P \geq 0.55)$ contraction protocol. Maximum torque generation did not differ between the hypoxia and sham conditions for the brief MVC protocol, as no time by condition interaction, and no main effect of condition, was observed. However, a main effect of time $\left(F_{2.581,62.8}=28.39, P<0.001\right)$ was detected for maximum torque, where post hoc analysis indicated that torque was lower at $0 \mathrm{hr}(P=0.003), 1 \mathrm{hr}(P=0.001)$, and $2 \mathrm{hr}(P<$ 0.001) time points compared to Pre measurements (Table 2). Similarly, maximum torque did not differ between the hypoxia and sham conditions for the sustained MVC protocol as no time by condition interaction, or a main effect of condition, was observed. However, a main effect of time was detected for maximum torque $\left(F_{2.268,46.88}=23.09, P<0.001\right)$, where post 
hoc analysis indicated that torque was lower at $1 \mathrm{hr}(P=0.003)$ and $2 \mathrm{hr}(P=0.004)$ time points compared to Pre measurements for the sustained MVC protocol (Table 2). A time by condition interaction $\left(F_{3,64}=5.27, P=0.002\right)$ and a main effect of condition $\left(F_{1,26}=13.34\right.$, $P=0.001)$ was observed for bicep $\mathrm{EMG}_{\mathrm{RMS}}$ for the sustained MVC protocol. Post hoc analysis revealed that bicep $\mathrm{EMG}_{\mathrm{RMS}}$ was greater during sham at the $2 \mathrm{hr}(P=0.03)$ time point compared to Pre measurements and was significantly lower at the $2 \mathrm{hr}$ time point during hypoxia $(P=0.001)$ when compared to sham (Table 2$)$.

\section{TABLE 2 HERE}

\section{Motor evoked potential (MEP)}

TMS was applied to the motor cortex to generate MEPs in the biceps brachii. MEP area was measured from each TMS pulse and then normalised to the area of the Mmax collected during the same contraction. No differences in Pre measurements were seen for MEP area during the brief $(P \geq 0.64)$ or sustained $(P \geq 0.1)$ contraction protocol. For the brief MVC protocol, a main effect of condition was observed for MEP area $\left(F_{1,7}=7.05, P=0.03\right)$, where MEP area for the hypoxia condition was greater than the sham condition during the maximal contraction intensity (Figure 4). No interaction effect or main effect of time was observed for the brief MVC. There were no main effects or interaction effects for $75 \%, 50 \%$, and $25 \%$ MVC intensities for the brief MVC protocol (Figure 4). In regards to the sustained MVC protocol, there were no main effects or interaction effects observed for any contraction intensities.

FIGURE 3 AND 4 HERE

This article is protected by copyright. All rights reserved. 


\section{Resting twitch, superimposed twitch, and voluntary activation}

Motor point stimulation was used to obtain resting and superimposed twitches from the biceps brachii during the hypoxia and sham condition. No differences in Pre measurements were seen for the resting twitch during the brief $(P=0.96)$ or sustained $(P=0.55)$ contraction protocol. For both the brief MVC protocol and the sustained MVC protocol, there were no condition-related or time-related main or interaction effects detected for resting twitch (Figure 6). Therefore, the level of $\mathrm{SpO}_{2}$ and the duration of the protocol did not affect the contractile properties of the muscle in either condition.

Similar to the resting twitch, there were no differences in Pre measurements seen for the superimposed twitch during the brief $(P=0.53)$ or sustained $(P=0.61)$ contraction protocol. There were no condition-related main effects for the superimposed twitch during the brief MVC protocol and the sustained MVC protocol. A condition by time interaction effect was detected for the superimposed twitch during the brief MVC protocol $\left(F_{3,45}=2.875, P=\right.$ 0.046), where post hoc analysis revealed that superimposed twitch at the $2 \mathrm{hr}$ time point was greater during hypoxia than the sham condition $(P=0.011)$. A main effect of time was identified only for the brief MVC protocol $\left(F_{2.078,31.16}=5.964, P=0.005\right)$, but not for the sustained MVC protocol, where superimposed twitch was greater from the $1 \mathrm{hr}$ time point compared to the Pre time point $(P=0.028)$. No interaction effects were identified for superimposed twitches during the sustained MVC protocol.

The level of VA was calculated from the resting twitch and superimposed twitch measurements. There were no differences in Pre measurements seen for level of VA during the brief $(P=0.82)$ or sustained $(P=0.41)$ contraction protocol. A main effect of condition was detected for VA during the brief MVC protocol where the hypoxia condition caused significantly lower activation compared to the sham condition $\left(F_{1,25}=7.319, P=0.012\right)$. A 
main effect of time was also detected for the brief MVC protocol $\left(F_{2.403,36.05}=14.58, P<\right.$ 0.001), where VA was lower at the $0 \mathrm{hr}(P=0.009), 1 \mathrm{hr}(P<0.001)$ and $2 \mathrm{hr}(P=0.002)$ time points compared to the Pre measurements during the hypoxia condition. No main effects of the condition or time, and no condition by time interaction was identified for VA during the sustained MVC protocol.

\section{FIGURE 5 AND 6 HERE}

\section{Rating of perceived fatigue}

During each hour of the protocol, the CR-10 Borg scale was employed immediately after each sustained MVC to determine the participant's perception of fatigue. Rating of perceived fatigue was then averaged across the three sustained MVCs. There were no differences in Pre measurements seen for rating of perceived fatigue $(P=0.56)$. There was a statistically significant median difference in perception of fatigue at the $1 \mathrm{hr}$ and $2 \mathrm{hr}$ time points $(P<$ 0.05), where participants perceived their muscle fatigue to be greater during hypoxia compared to sham (Figure 7).

\section{FIGURE 7 HERE}

\section{DISCUSSION}

The purpose of this study was to examine how a predetermined level of acute hypoxia alters central and peripheral mechanisms that underlie neuromuscular changes induced by maximal effort contractions. Our main findings were: 1) motor cortex excitability increased with hypoxic exposure when performing brief MVCs; 2) VA of the biceps brachii was reduced during brief MVCs due to hypoxic exposure; 3) these changes in motor function due to hypoxic exposure were not present after performing a sustained MVC; and 4) perception of 
fatigue was enhanced throughout testing, which started immediately after reducing blood oxygen concentration to $80 \% \mathrm{SpO} 2$.

\section{Hypoxia-induced hyperexcitability of corticospinal motor pathways}

Changes in TMS-induced MEP area reflect changes in corticospinal motor pathways (Barker, Jalinous, \& Freeston, 1985). In the current study, elbow flexor MEP area was larger in the hypoxia condition compared to the sham condition, but only when performing maximal contractions (and not submaximal contractions). The emergence of enhanced excitability across the entire protocol suggests that the impact of reduced $\mathrm{SpO}_{2}$ on corticospinal pathways is substantial during acute hypoxia. Although the current study identified a ubiquitous enhancement in corticospinal excitability, this contrasts with previous hypoxia studies that have identified a 2-3 hr delay in motor unit firing changes (McKeown et al., 2019) and corticospinal excitability changes of the lower limb (Rupp et al., 2012). Similarly, neural excitability adaptations were only evident when performing MVC, which is contrary to previous research examining the lower limb (Rupp et al., 2012). Given that MEP area was not affected for the submaximal contraction intensities, it appears that the underlying motor state (for biceps brachii) where acute hypoxia affects corticospinal excitability is one that requires activation of highest threshold motoneurons. As motoneurons within spinal and supraspinal sites become hyperexcitable in exposure to acute hypoxia (Christiansen, Urbin, Mitchell, \& Perez, 2018; Rupp et al., 2012), this change in excitability would be most evident during brief maximal contractions where the majority of motoneurons are active before transitioning into refractory states.

Interestingly, an increase in corticospinal excitability was only evident during the brief MVC and not following a sustained MVC. In vitro studies have found that severe exposures to

This article is protected by copyright. All rights reserved. 
hypoxia induce progressive reductions in the firing rate of neurons, which can be attenuated by restoring oxygen availability (Boychuk, Woerman, \& Mendelowitz, 2012; Dergacheva, Yamanaka, Schwartz, Polotsky, \& Mendelowitz, 2016). This highlights the importance of dynamic regulation of blood flow, where the delivery of oxygen-rich blood can reduce hypoxic effects in active neural circuits (Marrett \& Gjedde, 1997). During severe hypoxic exposures $\left(<0.15 \mathrm{~F}_{\mathrm{I}} \mathrm{O}_{2}\right)$ dynamic cerebral autoregulation is disrupted, which results in the inability to accurately match the metabolic demand of neurons in the cortex (Horiuchi et al., 2016; Rasmussen et al., 2010). However, a longer duration contraction provides a greater stimulus for increased blood flow to active neurons in the cortex and spinal cord, supporting metabolic activity of active neurons (Liu et al., 2003) . Under normal physiological conditions, biceps brachii MEP size decreases at forces beyond 75-90\% MVC, as very rapid discharge rates will lead to a greater number of motoneurons being refractory at the time of stimulus delivery (Martin, Gandevia, \& Taylor, 2006). Thus, it is possible the brief $3 \mathrm{~s}$ MVC was not long enough to allow adequate redistribution of oxygen-rich blood, resulting in disruption to oxygen delivery to activated motoneurons before assessing excitability of corticospinal motor pathways. Depression of motoneuron firing rate would have occurred, resulting in a larger MEP. However, the sustained MVC may have been long enough to allow subtle redistribution of blood flow to meet the metabolic demand of active motoneurons, restoring motoneuron firing rate and preventing any increases in MEP size.

\section{Acute hypoxia-related changes in voluntary activation}

Motor point stimulation was used to obtain superimposed and resting twitches to provide an estimation of the ability to voluntarily activate that muscle. A superimposed twitch generated during the performance of an MVC indicates that not all motoneurons are recruited during the

This article is protected by copyright. All rights reserved. 
contraction, or they are firing at submaximal rates (Herbert \& Gandevia, 1999). In contrast, a resting twitch generated in the relaxed muscle provides insight to contractile properties of the muscle itself, and is commonly used as an indicator of peripheral fatigue (Todd, Taylor, \& Gandevia, 2004). In the current study, reducing $\mathrm{SpO}_{2}$ to $80 \%$ did not affect the contractile properties of the muscle, as the resting twitch did not differ between the sham and hypoxia conditions at any time point. However, the recruitment or discharge of motoneurons during the brief MVC was impaired following $2 \mathrm{hr}$ of hypoxic exposure, as the superimposed twitch was greater during the hypoxia condition compared to the sham condition. This resulted in a reduction in VA of the biceps brachii when performing brief maximal contractions, which is consistent with other elbow flexor studies that show a hypoxia-induced reduction of VA during brief MVCs (Rasmussen et al., 2010; Ruggiero et al., 2018).

Unlike the brief $3 \mathrm{~s}$ MVC protocol, VA during the sustained $20 \mathrm{~s}$ MVC protocol was consistent with the MEP findings. Given that group III/IV muscle afferent activity is a primary cause of central fatigue (Arbogast, Vassilakopoulos, Darques, Duvauchelle, \& Jammes, 2000; Gandevia, Allen, Butler, \& Taylor, 1996), the failure of VA to decline from measurement made pre-titration suggests that this afferent input was insufficient to impair VA and was not exacerbated during hypoxia. As proposed when discussing the MEP data, the equivalent VA response for hypoxia and sham conditions suggests the sustained MVCs induced a large enough haemodynamic response (redistribution of blood) to overcome the lower blood oxygenation during hypoxia. Furthermore, it appears that the torque reduction from Pre measurements during the sustained MVCs was mitigated compared to the brief MVCs (refer to Table 2), which reinforces the proposition of increased blood flow. There is considerable support for this in studies of activity-dependent muscle and CNS blood distribution, where neural and muscle metabolism during exercise causes a redistribution of blood flow to enhance oxygenation in active tissue (Amann, Runnels, et al., 2011;

This article is protected by copyright. All rights reserved. 
Cunnington, Windischberger, Deecke, \& Moser, 2002; Ide, Horn, \& Secher, 1999; Liu et al., 2003; Sheel, Boushel, \& Dempsey, 2018). Although the current study cannot pinpoint the exact location in the motor or pulmonary system where these changes are occurring, our study highlights clear differences between muscle contractions of differing durations during acute hypoxia.

\section{Perception of fatigue during hypoxia}

The CR-10 Borg Scale is primarily used to assess perceptions of voluntary exertion during exercise; however, we used the scale to subjectively measure the participants perception of muscle fatigue after performing the sustained contraction task. During acute hypoxia, perception of exertion is reported to be enhanced during sustained exercise tasks (Goodall, Twomey, Amann, et al., 2014; Romer, Haverkamp, Lovering, Pegelow, \& Dempsey, 2006; Ruggiero et al., 2018), alongside increases in corticospinal excitability (Goodall, Twomey, Amann, et al., 2014; Ruggiero et al., 2018). To date, little is known about the link between corticospinal excitability, perception of fatigue, and disruption in oxygen delivery to the CNS. In post-stroke patients, those with higher perceptions of muscle fatigue and effort also have higher motor thresholds and lower corticospinal excitability (Kuppuswamy, Clark, Turner, Rothwell, \& Ward, 2015). A similar relationship between perception of fatigue and corticospinal excitability may also occur during the hypoxic protocol in the current study, however further investigation is required. It could be argued that the changes seen in VA and corticospinal excitability are simply due to a lack of motivation, due to the presence of AMS symptoms and enhanced fatigue perception. However, AMS symptoms were mild in the present study and force output did not differ between conditions, which suggests any neuralderived fatigue measure is likely a mechanism of hypoxia involving motor pathways rather than perception or motivation.

This article is protected by copyright. All rights reserved. 


\section{Clinical relevance}

While the current study recruited healthy individuals, our findings may have relevance for selected clinical populations. Well-known disorder such as chronic obstructive pulmonary disease (COPD), ischemic stroke, and congestive heart failure, may induce substantial reductions in oxygen availability to neural and muscular tissues. A consequence of this reduced oxygen availability is the emergence of motor dysfunction and reduced exercise capacity (Bekfani et al., 2016; Cauraugh, Light, Kim, Thigpen, \& Behrman, 2000; Jones et al., 2015; Silva, Gomes Neto, Saquetto, Conceicao, \& Souza-Machado, 2018). Common physical rehabilitation strategies for each disorder have not only employed lower limb locomotor exercise, but have also employed upper limb resistance exercise, in an effort to enhance motor function and overall well-being (Park et al., 2017; Silva et al., 2018). Based on our findings, it is possible that prolonged isometric contractions of upper limb muscle are minimally impacted by hypoxia. However, this viewpoint should be approached with caution, as the above-mentioned pathologies are typically life-long chronic conditions where 1) the ability of the nervous system to accommodate for changes in oxygen availability may be progressively impaired with longer disease durations, and 2) co-morbidities may develop that compromise motor function via mechanisms that do not involve oxygen availability. Moreover, the merit of undertaking prolonged isometric contraction protocols for motor rehabilitation would need further development, as there is contrasting views on the benefit and risk of clinical populations performing isometric contractions (Caldas et al., 2018; Patten, Condliffe, Dairaghi, \& Lum, 2013). Further research is warranted in clinical populations to determine if the duration and intensity of muscle contractions exacerbates hypoxia-related changes in motor function.

This article is protected by copyright. All rights reserved. 


\section{Considerations}

Sufficient rest was given between the brief and sustained MVC protocols as well as across each experimental time point. However, due to the decline in force during both the brief and sustained MVC protocols, an accumulation of fatigue was evident. Additionally, three cortical stimulations were used to assess corticospinal excitability, where other studies have used a greater number of stimulations (Taylor, Butler, Allen, \& Gandevia, 1996; Zijdewind, Butler, Gandevia, \& Taylor, 2006), which is beneficial as to reduce variability in the measurement of corticospinal excitability. Our study design purposefully incorporated a discrete number of contractions to ensure participants maintained a strict and limited exposure to hypoxia, while conducting repetitive stimulations over a short period of time to maintain the testing schedule. Although fatigue was present, the within-subject design accounted for this, as each subject acted as their own control. During the sustained MVC, torque reduced to a similar extent in both the sham and hypoxia conditions. However, a greater reduction in $\mathrm{EMG}_{\mathrm{RMS}}$ was seen during hypoxia (refer to Table 2). This dissociation between EMG and force is seen in studies that employ surface EMG measurements (Buchanan, Rovai, \& Rymer, 1989; Stutzig \& Siebert, 2015), and is explained by changes in activity from (unmeasured) synergistic muscles that contribute to the force that is being measured (Allen, McKenzie, \& Gandevia, 1998). The majority of movements that a human can perform is regulated by two or more muscles, so any measurement of force is unlikely to be linearly related to the surface EMG of one muscle alone. We believe that hypoxia related differences that emerged in EMG but not force can be attributed to the recruitment of other muscles during the task.

This article is protected by copyright. All rights reserved. 


\section{Conclusion}

This study aimed to assess the effect that acute hypoxia has on the central and peripheral mechanisms that underlie maximal muscle activation. A time-dependent hypoxia related effect emerged for perception of fatigue, where perception was progressively enhanced throughout the protocol. Corticospinal excitability increased with hypoxic exposure when performing brief MVCs, whereas VA of the biceps brachii was reduced during brief MVCs due to hypoxic exposure. Given that these changes in MEP area and VA were only seen when performing the brief $3 \mathrm{~s} \mathrm{MVCs} \mathrm{and} \mathrm{not} \mathrm{during} \mathrm{the} \mathrm{sustained} 20 \mathrm{~s} \mathrm{MVCs,} \mathrm{it} \mathrm{is} \mathrm{possible} \mathrm{that}$ performing a somewhat longer contraction may overcome reduced oxygen content via a secondary mechanism that was not examined in this study (e.g. redirecting blood flow or changes in perfusion).

\section{Competing interests and funding}

The authors declare that no competing interests exist and no funding was obtained for this work.

\section{Author contributions}

All authors contributed to the conception and design of this work, as well as the drafting and final approval of the manuscript. Data collection and analysis was performed by DJM at Griffith University, Australia.

This article is protected by copyright. All rights reserved. 


\section{Data availability statement}

The data that support the findings of this study are available from the corresponding author upon reasonable request.

\section{Acknowledgements}

We would like to express our gratitude to all the participants involved in our study, for their support and patience, and for contributing their time.

\section{TABLES}

Table 1. Lake Louise acute mountain sickness (AMS) survey scores for symptoms of headache, nausea, sleepiness and dizziness, as either: 0 (absent); 1 (mild); 2 (moderate); or 3 (severe).

\begin{tabular}{|c|c|c|c|c|c|c|c|c|}
\hline & \multicolumn{2}{|c|}{ Pre } & \multicolumn{2}{|c|}{$0 \mathrm{hr}$} & \multicolumn{2}{|c|}{$1 \mathrm{hr}$} & \multicolumn{2}{|c|}{$2 \mathrm{hr}$} \\
\hline & Sham & Нypoxia & Sham & Нypoxia & Sham & Hypoxia & Sham & Нypoxia \\
\hline Headache & 0 & 0 & 0 & $\begin{array}{c}0.07 \pm \\
0.26\end{array}$ & 0 & $\begin{array}{c}0.21 \pm \\
0.43\end{array}$ & 0 & $\begin{array}{c}0.29 \pm \\
0.61\end{array}$ \\
\hline Nausea & 0 & 0 & 0 & $\begin{array}{c}0.07 \pm \\
0.27\end{array}$ & 0 & $\begin{array}{c}0.14 \pm \\
0.36\end{array}$ & 0 & $\begin{array}{c}0.29 \pm \\
0.47\end{array}$ \\
\hline Sleepiness & 0 & 0 & $\begin{array}{c}0.29 \pm \\
0.61\end{array}$ & $\begin{array}{c}0.64 \pm \\
0.75\end{array}$ & $\begin{array}{c}0.43 \pm \\
0.76\end{array}$ & $\begin{array}{c}1.07 \pm \\
0.83\end{array}$ & $\begin{array}{c}0.36 \pm \\
0.63\end{array}$ & $\begin{array}{c}1.36 \pm \\
0.75\end{array}$ \\
\hline Dizziness & 0 & 0 & 0 & $\begin{array}{c}0.07 \pm \\
0.27\end{array}$ & 0 & $\begin{array}{c}0.29 \pm \\
0.61\end{array}$ & 0 & $\begin{array}{c}0.29 \pm \\
0.61\end{array}$ \\
\hline
\end{tabular}

Data are mean $\pm \mathrm{SD}$

This article is protected by copyright. All rights reserved. 
Table 2. Difference in maximal voluntary torque and root mean square amplitude of biceps brachii electromyography (EMG $\mathrm{RMS}_{\mathrm{S}}$ ) from Pre measurements for the brief ( $3 \mathrm{~s}$ ) maximal voluntary contraction (MVC) protocol and after sustained (20 s) MVC protocol.

\begin{tabular}{|c|c|c|c|c|}
\hline & \multicolumn{2}{|c|}{ Brief MVC protocol } & \multicolumn{2}{|c|}{20 s MVC protocol } \\
\hline $\begin{array}{l}\text { Maximal torque } \\
\text { (N.m) }\end{array}$ & Sham & Hypoxia & Sham & Hypoxia \\
\hline $0 \mathrm{hr}$ & $-9.99 \pm 8.93 *$ & $-5.62 \pm 4.28 *$ & $-4.98 \pm 6.34$ & $-1.22 \pm 3.84$ \\
\hline $1 \mathrm{hr}$ & $\begin{array}{c}-12.39 \pm \\
8.93^{*}\end{array}$ & $-12.84 \pm 9.98^{*}$ & $-6.45 \pm 4.76^{*}$ & $-4.59 \pm 3.71 *$ \\
\hline $2 \mathrm{hr}$ & $\begin{array}{c}-13.46 \pm \\
9.96^{*}\end{array}$ & $\begin{array}{c}-13.45 \pm \\
10.43^{*}\end{array}$ & $-7.66 \pm 6.88^{*}$ & $-9.13 \pm 6.89 *$ \\
\hline $\mathbf{E M G}_{\text {RMS }}(\mathrm{mV})$ & & & & \\
\hline $0 \mathrm{hr}$ & $-0.02 \pm 0.08$ & $0.002 \pm 0.12$ & $-0.02 \pm 0.13$ & $-0.02 \pm 0.12$ \\
\hline $1 \mathrm{hr}$ & $0.02 \pm 0.20$ & $0.02 \pm 0.11$ & $0.08 \pm 0.14$ & $0.04 \pm 0.23$ \\
\hline $2 \mathrm{hr}$ & $0.01 \pm 0.12$ & $0.03 \pm 0.07$ & $0.08 \pm 0.13^{*}$ & $-0.10 \pm 0.11^{\dagger}$ \\
\hline
\end{tabular}

Significantly different from sham measurements

This article is protected by copyright. All rights reserved. 


\section{FIGURE CAPTIONS}

Figure 1. Participants were exposed to either a sham or a hypoxia condition that titrated peripheral blood oxygen saturation $\left(\mathrm{SpO}_{2}\right)$ to $80 \%$ over a 15 min period. Blocks of measurements were obtained before titration (Pre), immediately following titration ( $0 \mathrm{hr}), 1$ $\mathrm{hr}$ after titration, and $2 \mathrm{hr}$ after titration $(A)$. Motor cortical transcranial magnetic stimulation (TMS), brachial plexus stimulation, and motor point stimulation were performed during 3 sets of contractions involving a brief $(3 \mathrm{~s}) \mathrm{MVC}(B)$ and 3 sets of contractions involving a sustained (20 s) MVC $(C)$. Motor point stimulation of the biceps brachii was used to determined voluntary activation (VA), whereas motor cortical TMS was used to obtain motor evoked potentials (MEP) during MVC, 75\% MVC, 50\% MVC, and 25\% MVC contraction intensities. All MEP data were normalised to the compound muscle action potential (Mmax) area obtained from brachial plexus stimulation during the same contraction.
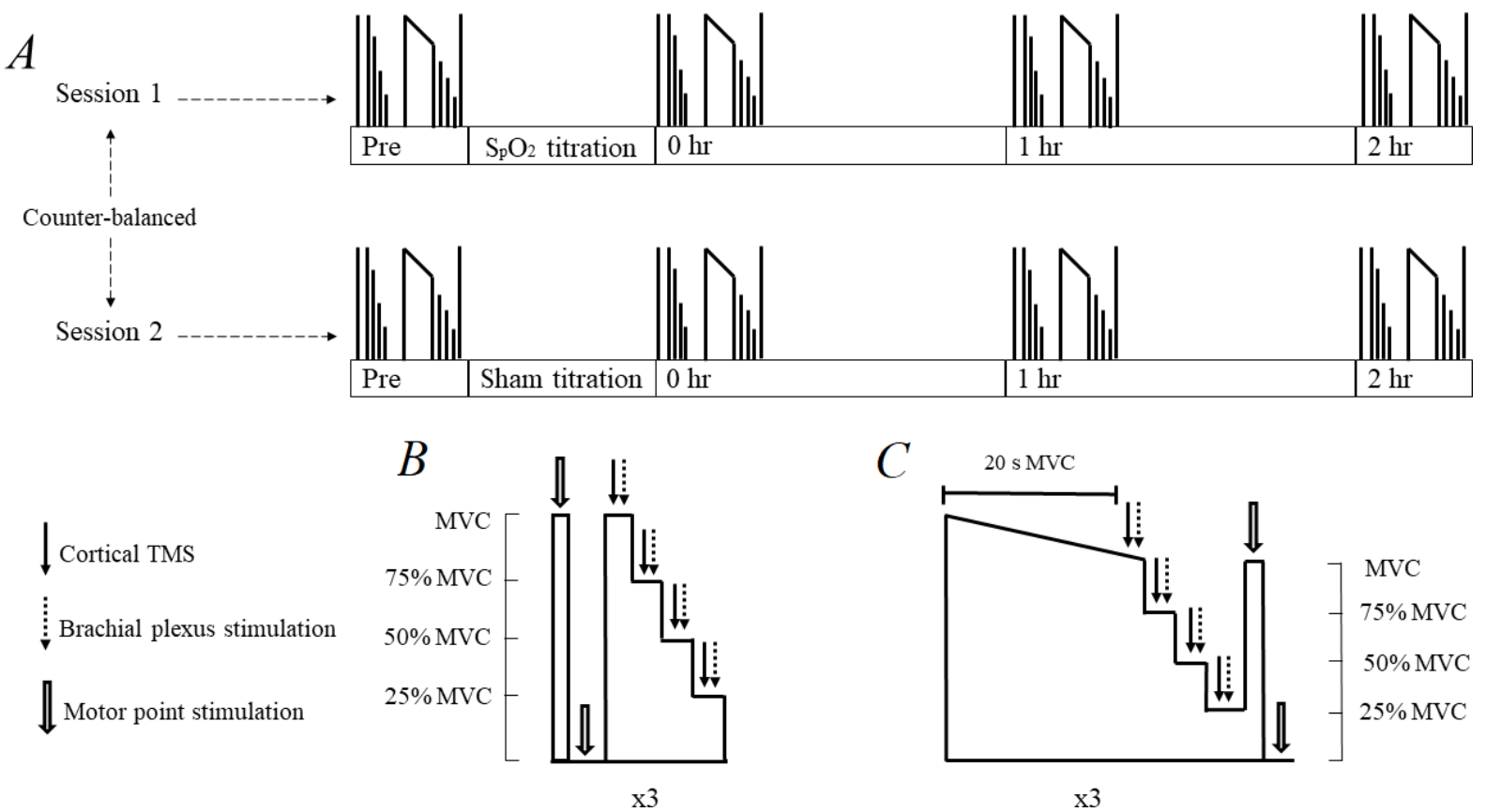

This article is protected by copyright. All rights reserved. 
Figure 2. The Lake Louise acute mountain sickness (AMS) survey scores. Self-reported data were obtained for the severity of dizziness, headaches, sleepiness, and nausea were accumulated to provide a single AMS measure (maximum score of 12). $A$. Individual accumulated AMS survey score of each participant at the beginning of each time point. $B$. The median change in the group AMS survey score at that time point, and error bars represent the range of the scores. There was a statistically significant median difference in AMS survey score at the $1 \mathrm{hr}$ and $2 \mathrm{hr}$ time points $(P<0.04)$, where participants experienced greater AMS symptoms during hypoxia compared to sham. Asterisks denote significant differences between conditions.
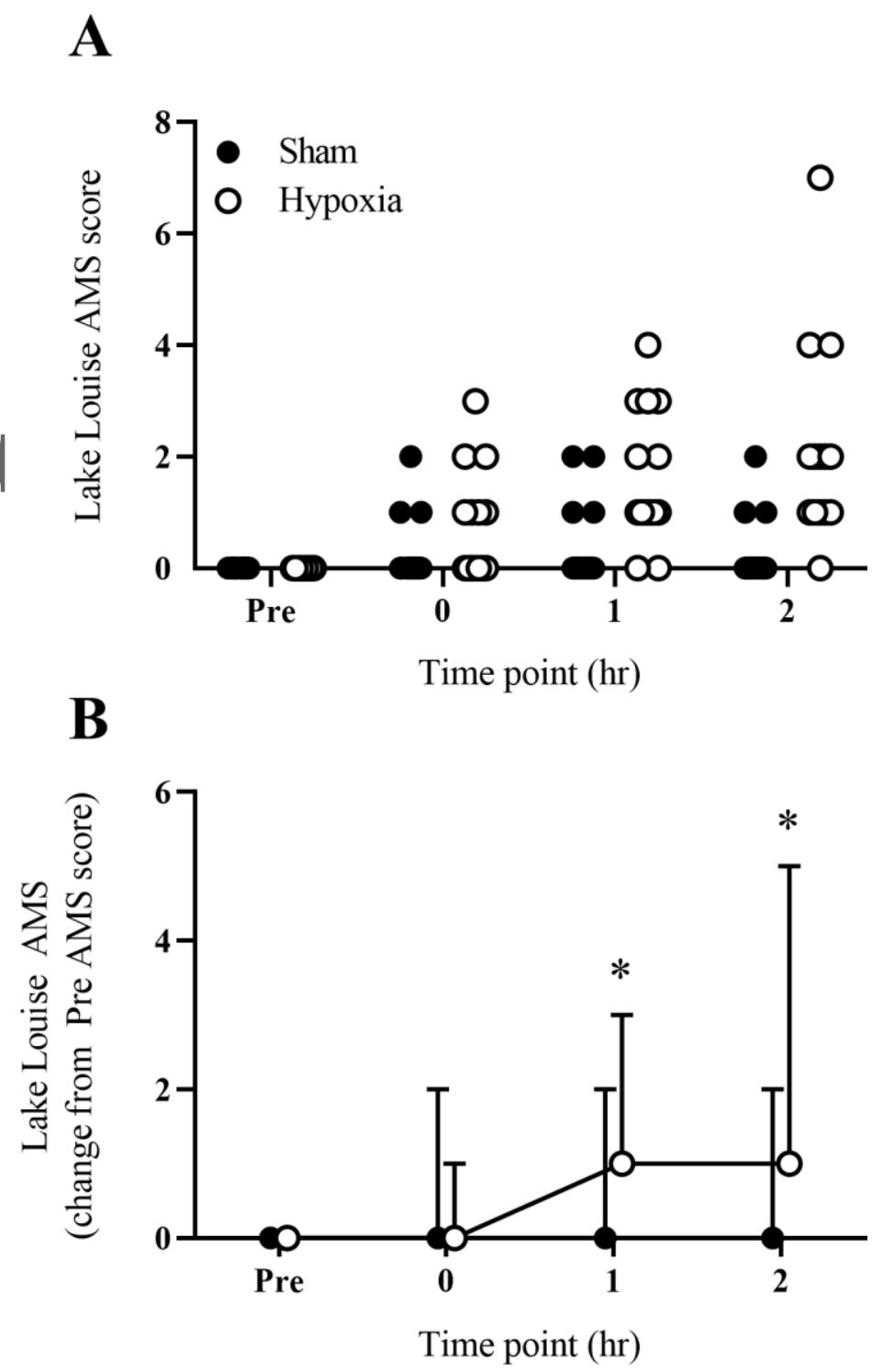

This article is protected by copyright. All rights reserved. 
Figure 3. Representative motor evoked potentials (MEP) from an individual participant during the brief MVC protocol at each contraction intensity.

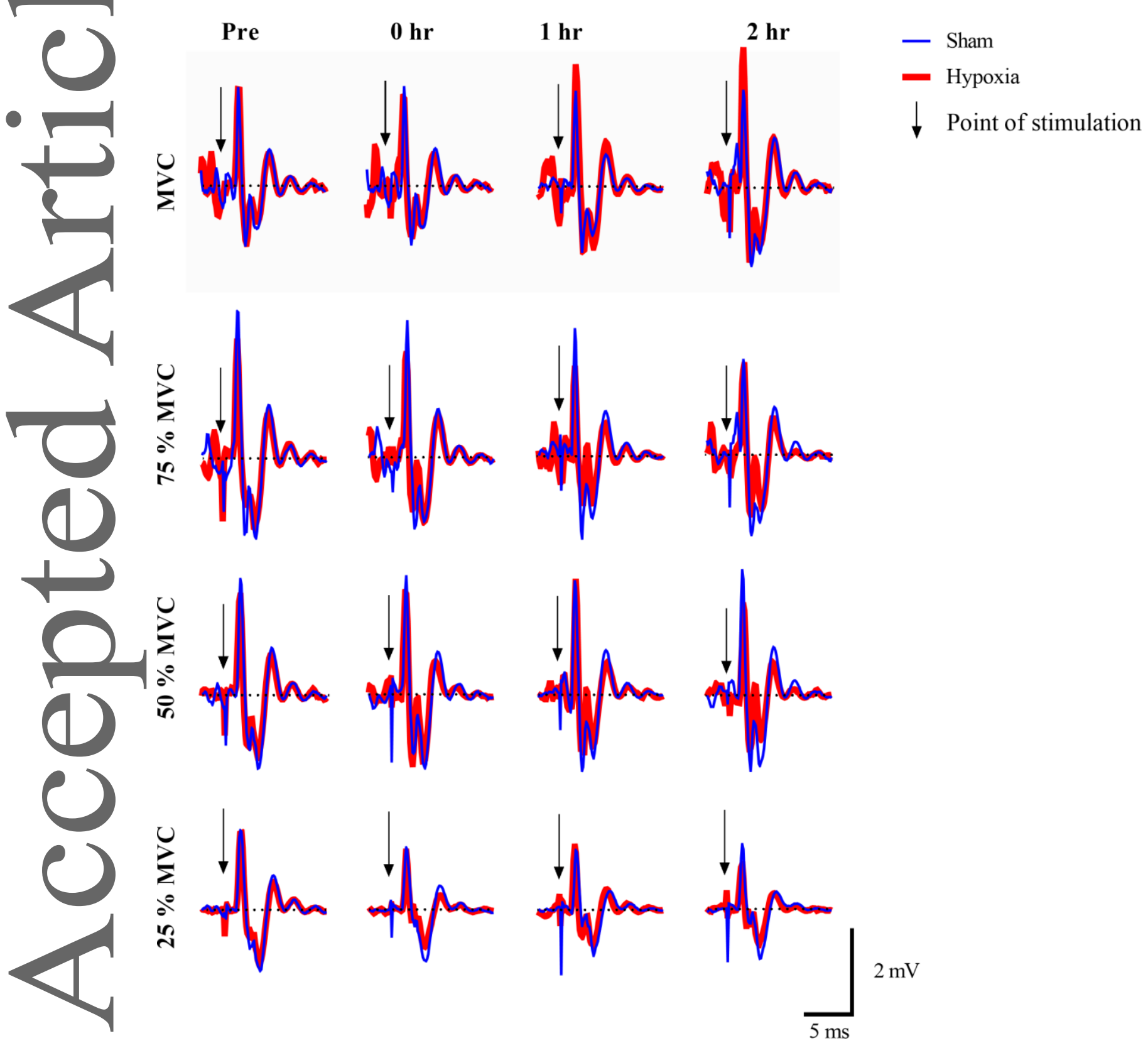

This article is protected by copyright. All rights reserved. 
Figure 4. Change in motor evoked potential (MEP) area from measurements collected pretitration. MEPs were normalised to the area of the maximal compound muscle action potential (Mmax) collected during the same contraction. Data represent the group mean at that time point, and error bars represent the standard deviation of the mean. Asterisk indicates significant main effect of condition $(P<0.05)$.
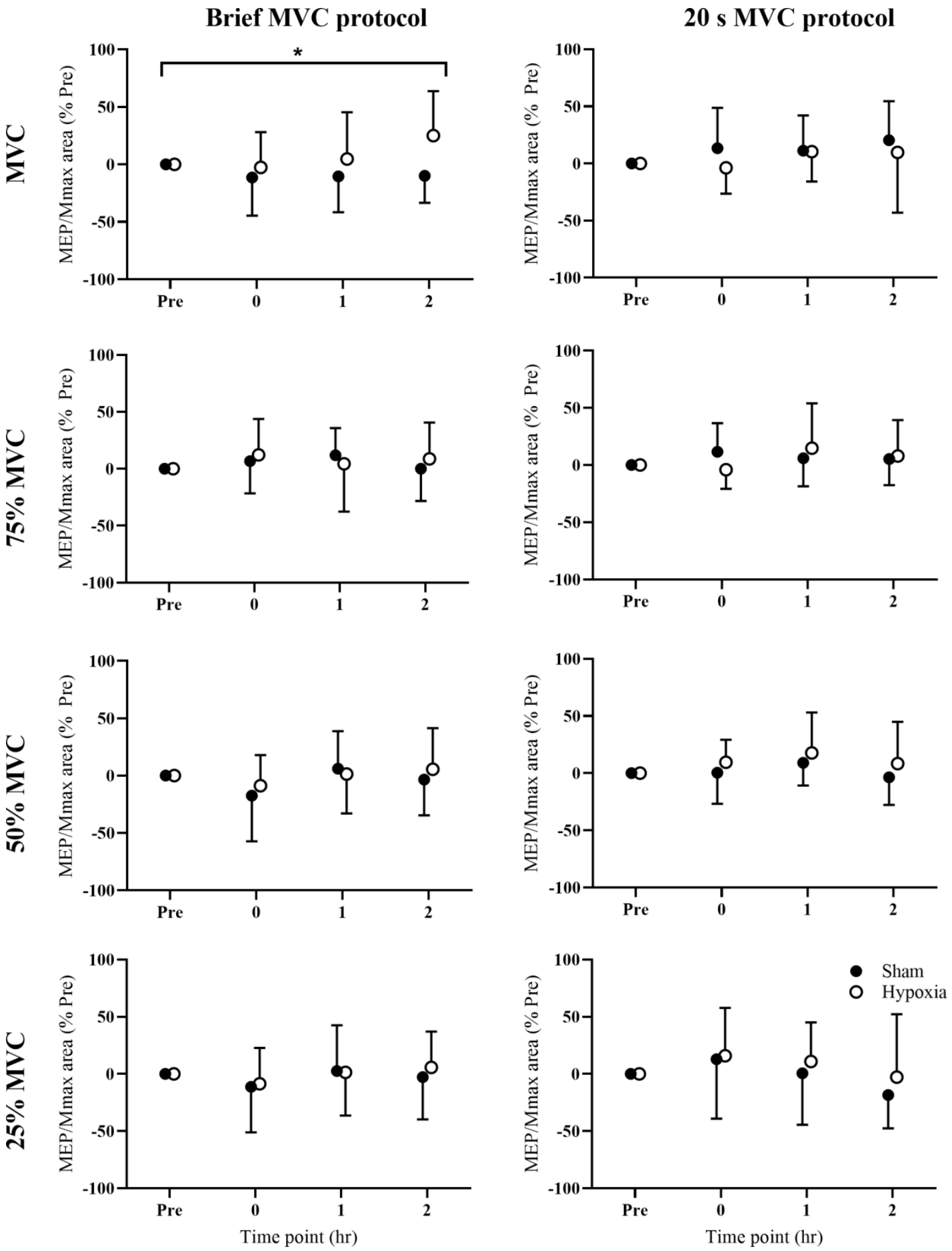

This article is protected by copyright. All rights reserved. 
Figure 6. Motor point resting twitch, superimposed twitch, and level of voluntary activation (VA) measured in unfatigued and fatigued muscle. Data represent the group mean at that time point, and error bars represent the standard deviation of the mean. Asterisks indicate main effect of condition and alpha indicates main effect of time $(P<0.05)$. Where an interaction effect was detected, crosses indicate difference from Pre time point, and double asterisk indicates difference between sham and hypoxia at that time point $(P<0.05)$.

Brief MVC protocol
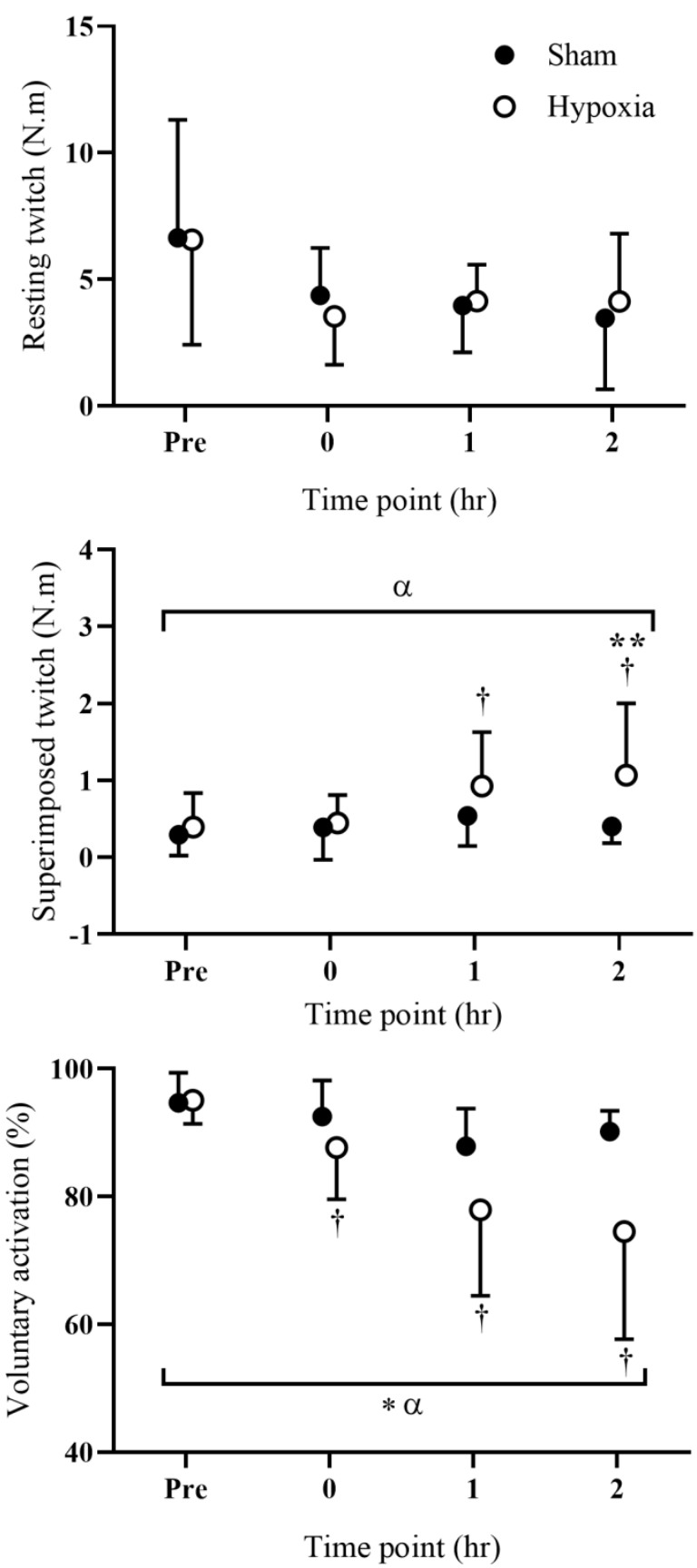

20s MVC protocol
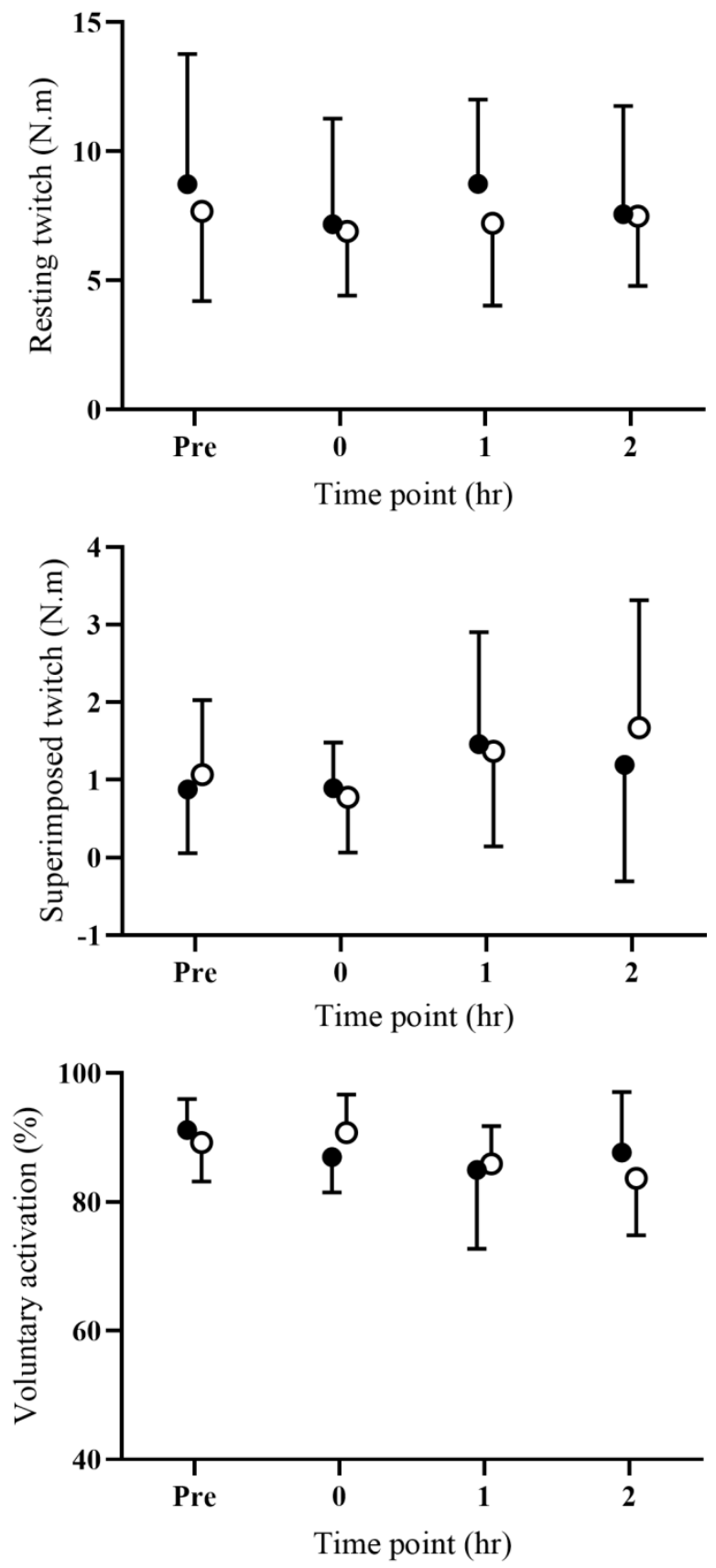

This article is protected by copyright. All rights reserved. 
Figure 7. Self-reported rating of perceived fatigue. During each hour of the testing protocol, the CR-10 Borg scale was employed immediately after completing the three sustained (20 s) MVCs. A. Mean rating of perceived fatigue of each participant after completing the sustained MVCs at each time point. $B$. The median change in rating of perceived fatigue of the group at each time point, and error bars represent the range of the ratings. There was a statistically significant median difference in perception of fatigue at the $1 \mathrm{hr}$ and $2 \mathrm{hr}$ time points $(P<$ 0.05), where participants perceived their muscle fatigue to be greater during hypoxia compared to sham. Asterisks denote significant differences between conditions.

A

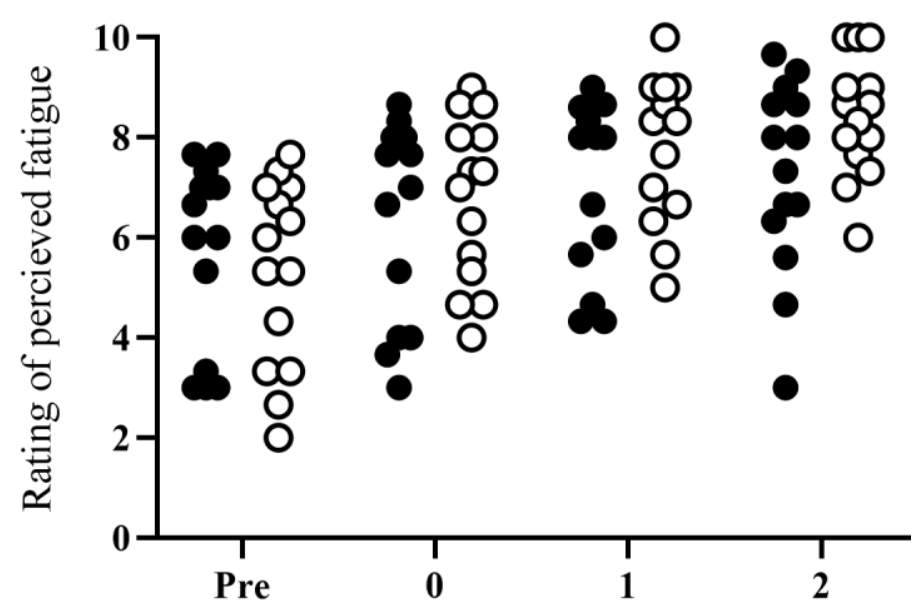

B

Time point (hr)

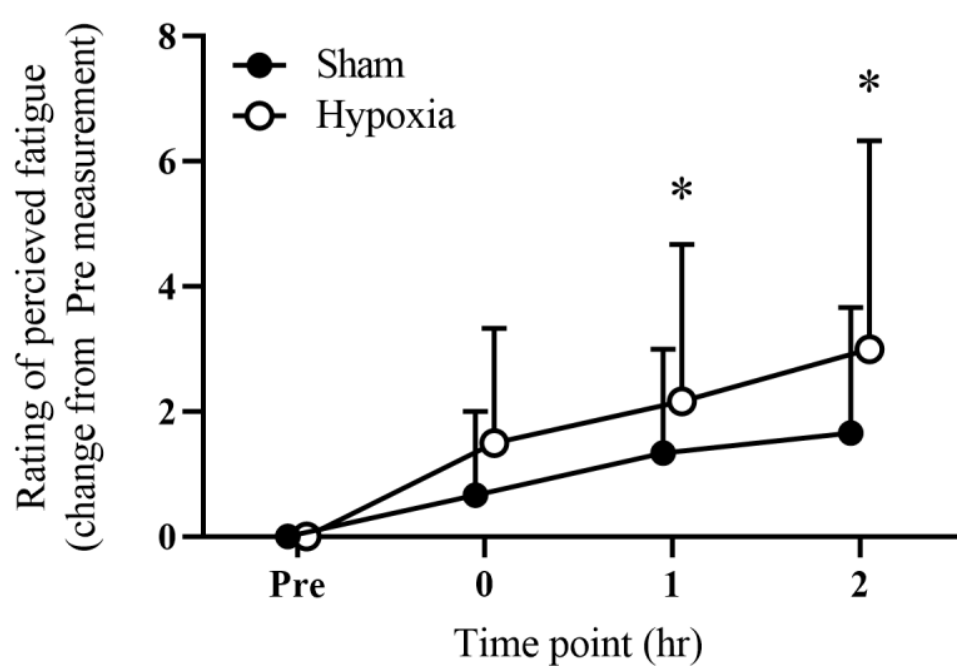

This article is protected by copyright. All rights reserved. 


\section{REFERENCES}

Allen, G. M., McKenzie, D. K., \& Gandevia, S. C. (1998). Twitch interpolation of the elbow flexor muscles at high forces. Muscle Nerve, 21(3), 318-328. doi:10.1002/(sici)10974598(199803)21:3<318::aid-mus5>3.0.co;2-d

Amann, M., Blain, G. M., Proctor, L. T., Sebranek, J. J., Pegelow, D. F., \& Dempsey, J. A. (2011). Implications of group III and IV muscle afferents for high-intensity endurance exercise performance in humans. J Physiol, 589(Pt 21), 5299-5309. doi:10.1113/jphysiol.2011.213769

Amann, M., Runnels, S., Morgan, D. E., Trinity, J. D., Fjeldstad, A. S., Wray, D. W., . . Richardson, R. S. (2011). On the contribution of group III and IV muscle afferents to the circulatory response to rhythmic exercise in humans. $J$ Physiol, 589(Pt 15), 3855-3866. doi:10.1113/jphysiol.2011.209353

Arbogast, S., Vassilakopoulos, T., Darques, J. L., Duvauchelle, J. B., \& Jammes, Y. (2000). Influence of oxygen supply on activation of group IV muscle afferents after low-frequency muscle stimulation. Muscle Nerve, 23(8), 1187-1193. doi:10.1002/10974598(200008)23:8<1187::aid-mus5>3.0.co;2-9

Barker, A. T., Jalinous, R., \& Freeston, I. L. (1985). Non-invasive magnetic stimulation of human motor cortex. Lancet, 1(8437), 1106-1107. doi:10.1016/s0140-6736(85)92413-4

Bekfani, T., Pellicori, P., Morris, D. A., Ebner, N., Valentova, M., Steinbeck, L., . . . von Haehling, S. (2016). Sarcopenia in patients with heart failure with preserved ejection fraction: Impact on muscle strength, exercise capacity and quality of life. Int J Cardiol, 222, 41-46. doi:10.1016/j.ijcard.2016.07.135

Billaut, F., Kerris, J. P., Rodriguez, R. F., Martin, D. T., Gore, C. J., \& Bishop, D. J. (2013). Interaction of central and peripheral factors during repeated sprints at different levels of arterial O2 saturation. PLoS One, 8(10), e77297. doi:10.1371/journal.pone.0077297

Borg, G. A. (1982). Psychophysical bases of perceived exertion. Med Sci Sports Exerc, 14(5), 377381. Retrieved from https://www.ncbi.nlm.nih.gov/pubmed/7154893

Boychuk, C. R., Woerman, A. L., \& Mendelowitz, D. (2012). Modulation of bulbospinal rostral ventral lateral medulla neurons by hypoxia/hypercapnia but not medullary respiratory activity. Hypertension, 60(6), 1491-1497. doi:10.1161/HYPERTENSIONAHA.112.197954

Buchanan, T. S., Rovai, G. P., \& Rymer, W. Z. (1989). Strategies for muscle activation during isometric torque generation at the human elbow. J Neurophysiol, 62(6), 1201-1212. doi:10.1152/jn.1989.62.6.1201

Caldas, J. R., Panerai, R. B., Salinet, A. M., Seng-Shu, E., Ferreira, G. S. R., Camara, L., . . Hajjar, L. A. (2018). Dynamic cerebral autoregulation is impaired during submaximal isometric handgrip in patients with heart failure. Am J Physiol Heart Circ Physiol, 315(2), H254-H261. doi:10.1152/ajpheart.00727.2017

Cauraugh, J., Light, K., Kim, S., Thigpen, M., \& Behrman, A. (2000). Chronic motor dysfunction after stroke: recovering wrist and finger extension by electromyography-triggered neuromuscular stimulation. Stroke, 31(6), 1360-1364. doi:10.1161/01.str.31.6.1360

Christiansen, L., Urbin, M. A., Mitchell, G. S., \& Perez, M. A. (2018). Acute intermittent hypoxia enhances corticospinal synaptic plasticity in humans. Elife, 7. doi:10.7554/eLife.34304

Cunnington, R., Windischberger, C., Deecke, L., \& Moser, E. (2002). The preparation and execution of self-initiated and externally-triggered movement: a study of event-related fMRI. Neuroimage, 15(2), 373-385. doi:10.1006/nimg.2001.0976

Dergacheva, O., Yamanaka, A., Schwartz, A. R., Polotsky, V. Y., \& Mendelowitz, D. (2016). Hypoxia and hypercapnia inhibit hypothalamic orexin neurons in rats. J Neurophysiol, 116(5), 2250-2259. doi:10.1152/jn.00196.2016

Gandevia, S. C., Allen, G. M., Butler, J. E., \& Taylor, J. L. (1996). Supraspinal factors in human muscle fatigue: evidence for suboptimal output from the motor cortex. J Physiol, 490 ( Pt 2), 529-536. doi:10.1113/jphysiol.1996.sp021164

This article is protected by copyright. All rights reserved. 
Goodall, S., Gonzalez-Alonso, J., Ali, L., Ross, E. Z., \& Romer, L. M. (2012). Supraspinal fatigue after normoxic and hypoxic exercise in humans. $J$ Physiol, 590(11), 2767-2782. doi:10.1113/jphysiol.2012.228890

Goodall, S., Ross, E. Z., \& Romer, L. M. (2010). Effect of graded hypoxia on supraspinal contributions to fatigue with unilateral knee-extensor contractions. J Appl Physiol (1985), 109(6), 1842-1851. doi:10.1152/japplphysiol.00458.2010

Goodall, S., Twomey, R., \& Amann, M. (2014). Acute and chronic hypoxia: implications for cerebral function and exercise tolerance. Fatigue, 2(2), 73-92. doi:10.1080/21641846.2014.909963

Goodall, S., Twomey, R., Amann, M., Ross, E. Z., Lovering, A. T., Romer, L. M., . . Roach, R. C. (2014). AltitudeOmics: exercise-induced supraspinal fatigue is attenuated in healthy humans after acclimatization to high altitude. Acta Physiol (Oxf), 210(4), 875-888. doi:10.1111/apha.12241

Herbert, R. D., \& Gandevia, S. C. (1999). Twitch interpolation in human muscles: mechanisms and implications for measurement of voluntary activation. J Neurophysiol, 82(5), 2271-2283. doi:10.1152/jn.1999.82.5.2271

Horiuchi, M., Endo, J., Dobashi, S., Kiuchi, M., Koyama, K., \& Subudhi, A. W. (2016). Effect of progressive normobaric hypoxia on dynamic cerebral autoregulation. Exp Physiol, 101(10), 1276-1284. doi:10.1113/EP085789

Ide, K., Horn, A., \& Secher, N. H. (1999). Cerebral metabolic response to submaximal exercise. $J$ Appl Physiol (1985), 87(5), 1604-1608. doi:10.1152/jappl.1999.87.5.1604

Jones, S. E., Maddocks, M., Kon, S. S., Canavan, J. L., Nolan, C. M., Clark, A. L., . . Man, W. D. (2015). Sarcopenia in COPD: prevalence, clinical correlates and response to pulmonary rehabilitation. Thorax, 70(3), 213-218. doi:10.1136/thoraxjnl-2014-206440

Kavanagh, J. J., McFarland, A. J., \& Taylor, J. L. (2019). Enhanced availability of serotonin increases activation of unfatigued muscle but exacerbates central fatigue during prolonged sustained contractions. J Physiol, 597(1), 319-332. doi:10.1113/JP277148

Kuppuswamy, A., Clark, E. V., Turner, I. F., Rothwell, J. C., \& Ward, N. S. (2015). Post-stroke fatigue: a deficit in corticomotor excitability? Brain, 138(Pt 1), 136-148. doi:10.1093/brain/awu306

Liu, J. Z., Shan, Z. Y., Zhang, L. D., Sahgal, V., Brown, R. W., \& Yue, G. H. (2003). Human brain activation during sustained and intermittent submaximal fatigue muscle contractions: an FMRI study. $J$ Neurophysiol, 90(1), 300-312. doi:10.1152/jn.00821.2002

Marrett, S., \& Gjedde, A. (1997). Changes of blood flow and oxygen consumption in visual cortex of living humans. Adv Exp Med Biol, 413, 205-208. doi:10.1007/978-1-4899-0056-2_22

Martin, P. G., Gandevia, S. C., \& Taylor, J. L. (2006). Output of human motoneuron pools to corticospinal inputs during voluntary contractions. J Neurophysiol, 95(6), 3512-3518. doi:10.1152/jn.01230.2005

McKeown, D., Simmonds, M. J., \& Kavanagh, J. J. (2019). Reduced blood oxygen levels induce changes in low threshold motor unit firing that align with the individual's tolerance to hypoxia. J Neurophysiol. doi:10.1152/jn.00071.2019

McNeil, C. J., Giesebrecht, S., Khan, S. I., Gandevia, S. C., \& Taylor, J. L. (2011). The reduction in human motoneurone responsiveness during muscle fatigue is not prevented by increased muscle spindle discharge. $J$ Physiol, 589(Pt 15), 3731-3738. doi:10.1113/jphysiol.2011.210252

Park, E., Kim, M. S., Chang, W. H., Oh, S. M., Kim, Y. K., Lee, A., \& Kim, Y. H. (2017). Effects of Bilateral Repetitive Transcranial Magnetic Stimulation on Post-Stroke Dysphagia. Brain Stimul, 10(1), 75-82. doi:10.1016/j.brs.2016.08.005

Patten, C., Condliffe, E. G., Dairaghi, C. A., \& Lum, P. S. (2013). Concurrent neuromechanical and functional gains following upper-extremity power training post-stroke. J Neuroeng Rehabil, 10, 1. doi:10.1186/1743-0003-10-1

Rasmussen, P., Nielsen, J., Overgaard, M., Krogh-Madsen, R., Gjedde, A., Secher, N. H., \& Petersen, N. C. (2010). Reduced muscle activation during exercise related to brain oxygenation and metabolism in humans. $J$ Physiol, 588(Pt 11), 1985-1995. doi:10.1113/jphysiol.2009.186767

This article is protected by copyright. All rights reserved. 
Rojas-Camayo, J., Mejia, C. R., Callacondo, D., Dawson, J. A., Posso, M., Galvan, C. A., . . Subhi, R. (2018). Reference values for oxygen saturation from sea level to the highest human habitation in the Andes in acclimatised persons. Thorax, 73(8), 776-778. doi:10.1136/thoraxjnl-2017-210598

Romer, L. M., Haverkamp, H. C., Lovering, A. T., Pegelow, D. F., \& Dempsey, J. A. (2006). Effect of exercise-induced arterial hypoxemia on quadriceps muscle fatigue in healthy humans. Am J Physiol Regul Integr Comp Physiol, 290(2), R365-375. doi:10.1152/ajpregu.00332.2005

Ruggiero, L., \& McNeil, C. J. (2019). Supraspinal Fatigue and Neural-evoked Responses in Lowlanders and Sherpa at 5050 m. Med Sci Sports Exerc, 51(1), 183-192. doi:10.1249/MSS.0000000000001748

Ruggiero, L., Yacyshyn, A. F., Nettleton, J., \& McNeil, C. J. (2018). UBC-Nepal expedition: acclimatization to high-altitude increases spinal motoneurone excitability during fatigue in humans. J Physiol, 596(15), 3327-3339. doi:10.1113/JP274872

Rupp, T., Jubeau, M., Wuyam, B., Perrey, S., Levy, P., Millet, G. Y., \& Verges, S. (2012). Timedependent effect of acute hypoxia on corticospinal excitability in healthy humans. $J$ Neurophysiol, 108(5), 1270-1277. doi:10.1152/jn.01162.2011

Rupp, T., Racinais, S., Bringard, A., Lapole, T., \& Perrey, S. (2015). Modulation of exercise-induced spinal loop properties in response to oxygen availability. Eur J Appl Physiol, 115(3), 471-482. doi:10.1007/s00421-014-3032-5

Sheel, A. W., Boushel, R., \& Dempsey, J. A. (2018). Competition for blood flow distribution between respiratory and locomotor muscles: implications for muscle fatigue. J Appl Physiol (1985), 125(3), 820-831. doi:10.1152/japplphysiol.00189.2018

Sidhu, S. K., Weavil, J. C., Venturelli, M., Garten, R. S., Rossman, M. J., Richardson, R. S., . . Amann, M. (2014). Spinal mu-opioid receptor-sensitive lower limb muscle afferents determine corticospinal responsiveness and promote central fatigue in upper limb muscle. $J$ Physiol, 592(22), 5011-5024. doi:10.1113/jphysiol.2014.275438

Silva, C., Gomes Neto, M., Saquetto, M. B., Conceicao, C. S. D., \& Souza-Machado, A. (2018). Effects of upper limb resistance exercise on aerobic capacity, muscle strength, and quality of life in COPD patients: a randomized controlled trial. Clin Rehabil, 32(12), 1636-1644. doi: $10.1177 / 0269215518787338$

Stutzig, N., \& Siebert, T. (2015). Muscle force compensation among synergistic muscles after fatigue of a single muscle. Hum Mov Sci, 42, 273-287. doi:10.1016/j.humov.2015.06.001

Szubski, C., Burtscher, M., \& Loscher, W. N. (2006). The effects of short-term hypoxia on motor cortex excitability and neuromuscular activation. J Appl Physiol (1985), 101(6), 1673-1677. doi:10.1152/japplphysiol.00617.2006

Szubski, C., Burtscher, M., \& Loscher, W. N. (2007). Neuromuscular fatigue during sustained contractions performed in short-term hypoxia. Med Sci Sports Exerc, 39(6), 948-954. doi:10.1249/mss.0b013e3180479918

Taylor, J. L., Butler, J. E., Allen, G. M., \& Gandevia, S. C. (1996). Changes in motor cortical excitability during human muscle fatigue. J Physiol, 490 ( Pt 2), 519-528. doi:10.1113/jphysiol.1996.sp021163

Todd, G., Taylor, J. L., \& Gandevia, S. C. (2004). Reproducible measurement of voluntary activation of human elbow flexors with motor cortical stimulation. J Appl Physiol (1985), 97(1), 236242. doi:10.1152/japplphysiol.01336.2003

Zijdewind, I., Butler, J. E., Gandevia, S. C., \& Taylor, J. L. (2006). The origin of activity in the biceps brachii muscle during voluntary contractions of the contralateral elbow flexor muscles. Exp Brain Res, 175(3), 526-535. doi:10.1007/s00221-006-0570-z

This article is protected by copyright. All rights reserved. 